\title{
Study on Twining Technologies Adopted by Bamboo Sutra Wrappers of the Tang Dynasty
}

\author{
Rulin Yang ${ }^{1} \&$ Yanghua Kuang ${ }^{2}$ \\ ${ }^{1}$ China National Silk Museum, Hangzhou, China \\ ${ }^{2}$ Hainan Normal University, Haikou, China \\ Correspondence: Rulin Yang, China National Silk Museum, NO.73-1 Yuhuangshan Road, Westlake District, \\ Hangzhou, 310002, China. Tel: 86-150-8866-1030. E-mail: missyrl@163.com
}

Received: June 4, $2020 \quad$ Accepted: June 15, $2020 \quad$ Online Published: July 22, 2020

doi:10.5539/ass.v16n8p61 URL: https://doi.org/10.5539/ass.v16n8p61

\begin{abstract}
Bamboo sutra wrapper is made of bamboo splints fastened together with silk threads using the warp twining method. Bamboo sutra wrappers dating to the Tang and Song dynasties are mainly found in Cave 17. They are usually in a rectangular shape with the geometrical, dotted or floral pattern which are quite favored in the Tang dynasty. Affected by Buddhism, sutra wrappers of this kind have also been found in other Asian countries such as Japan and Korea, with a similarity in structure, dimension and twining method.
\end{abstract}

Keywords: Bamboo sutra wrapper, silk threads, Tang dynasties, Buddhism, twining method

\section{Introduction}

The Chinese character zhi means book wrappers or small bags. Jingzhi means sutra wrappers, which were used to store and protect Buddhist sutras in ancient times. Sutra wrappers are of various materials and constructions. Some are decorated with ties and some are not. The decorations' forms and functions are various. Bamboo sutra wrappers are made of flat bamboo splints and silk threads by the method of twining. Twining is an ancient hand weaving technique. Two sets of threads are required when apply twining. A set of threads should be laid in parallel while the other set twining around the former set. Twining appears in many ancient Chinese documents. Xiao Tong, a litterateur of the Southern dynasties (from 420 to 589 CE), wrote in $F u$ shuzhi [A Poem Dedicated to book wrappers]: "It is lucky that there are book wrappers made of colourful silk and the wrappers are woven by beautiful ladies." Lu You, another litterateur, wrote in RuShu ji [Journey to Sichuan]: "The poem collections of Bai Juyi have once been left in Bai's house then moved several times. The emperor Zhenzong demanded the royal library to compile and edit those poems into a book then cover with a bamboo book wrapper and send to the temple."

Most of the twined Buddhist sutra wrappers of the Tang and Song dynasties (from 618 to 1279 CE) were excavated from the Dunhuang library cave (Cave 17). However, at the beginning of the 20th century many of them were taken abroad by foreign archaeologists and have been collected in several museums or libraries overseas such as the British Museum, the Musée Guimet and the Bibliothèque nationale de France etc. Only a very few fragments are collected in Lüshun Museum.

\section{Construction of Sutra Wrappers}

Bamboo sutra wrappers can be quite frequently seen in the documents from Dunhuang.Citing the records in document numbered Meng 1704 (Дх1058) as a typical example, Dr. Fang Guangchang has proved that bamboo sutra wrappers were once very popular at Dunhuang. The document says: " 6 bamboo wrappers for Benxingji jing [Sutra of the Collection of the Original Acts of the Buddha], a bamboo sutra wrapper for Fa ji jing, a bamboo sutra wrapper for $\square \backslash \square$ lun jing, a bamboo sutra wrapper for Dafang deng dayu jing, a bamboo sutra wrapper for Guanfo sanmeihai jing". Bamboo sutra wrappers are also mentioned in the document numbered S.5594, which are divided into two types - crudely made and carefully-crafted.

Chinese bamboo sutra wrappers are all rectangular in shape. The ratio of length to width ranges from 1.2 to 1.6. Mostly, yellowish brown bamboo splints are used as wefts while Z-twisted silk threads in various colours are adopted as warps. Stripes of pattern of different widths, generally 9 in total including 4 wide ones and 5 narrow ones, are created by two silk threads in different colours twining with bamboo splints. The distance between each 
two stripes varies from $1 \mathrm{~cm}$ to $1.5 \mathrm{~cm}$ (see Figure 1). None of the survived Bamboo sutra wrappers is complete. Some are even with large areas missing. Some have been stained and the pattern can not be identified.

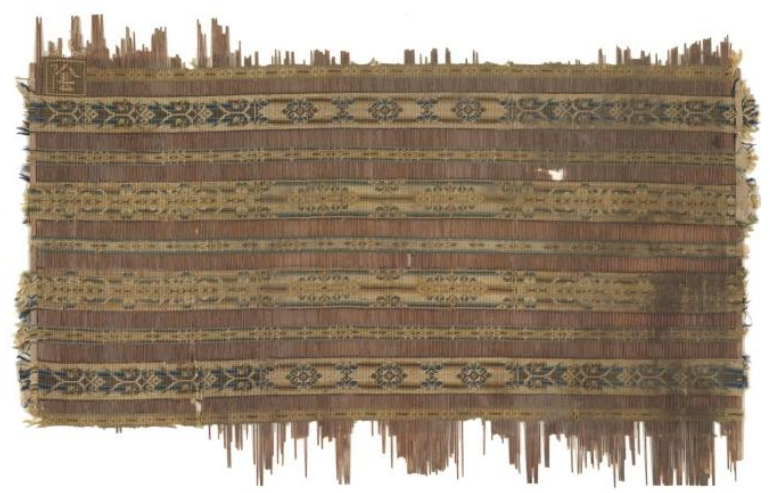

Figure 1. Bamboo sutra wrappers MAS.859

\section{Materials for Sutra Wrappers}

The comparatively well preserved sutra wrappers suggest that necessary materials for making sutra wrappers are bamboo splints and silk threads. Some sutra wrappers are finished by using textiles (such as EO.1209/I shown in Figure 2). Some are pasted with paper documents on the back (such as EO.1208 shown in Figure 3).
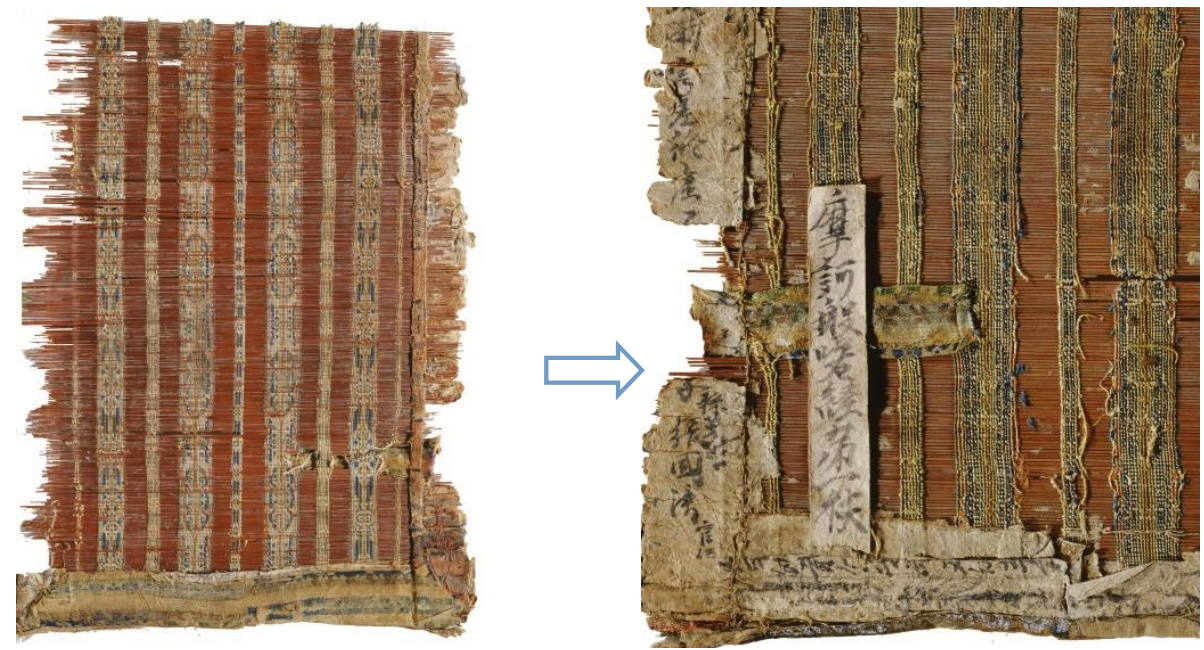

Figure 2. Bamboo sutra wrapper EO.1209, front and part of back
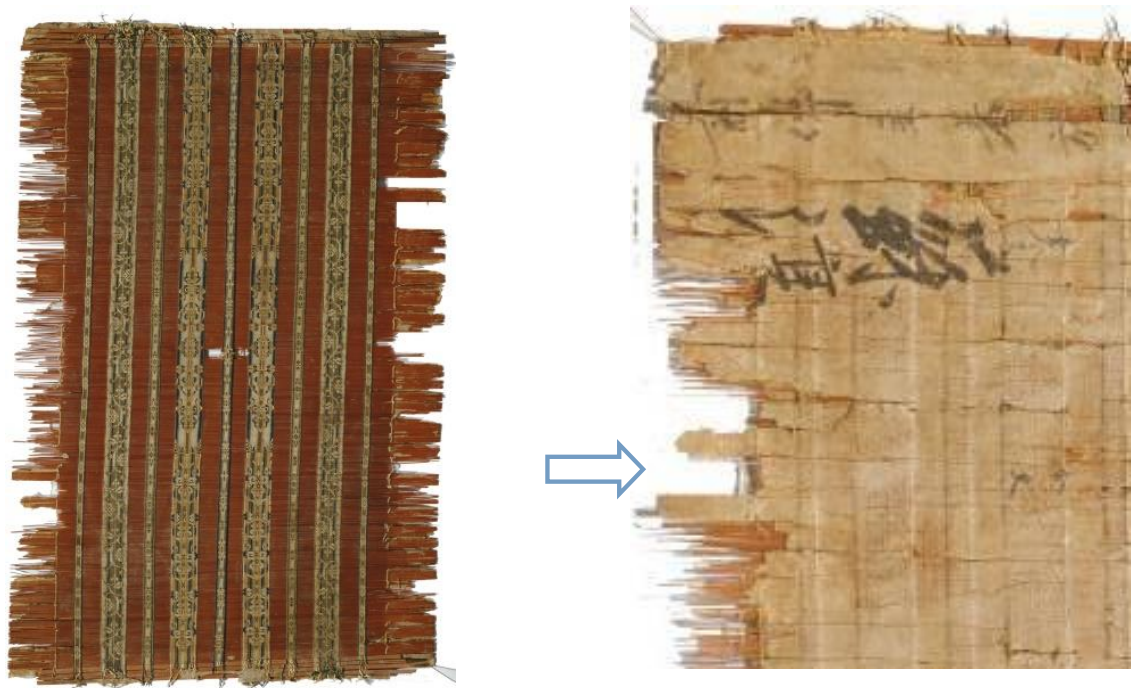

Figure 3. Bamboo sutra wrapper EO.1208, front and part of back 
Compared with wrappers made of other materials such as textiles, bamboo sutra wrapper are more sturdy and durable. They act as a sound protector of Buddhist documents. The finely made and smooth bamboo splints are mostly in the colour of reddish brown, which are created by careful dyeing. There are 9-13 bamboo splints in very width of $1 \mathrm{~cm}$. The lengths of bamboo splints vary from $26.8-32 \mathrm{~cm}$, which is determined by the size of Buddhist document. The colours of silk threads are multiple. The most common colours are cream, yellowish brown, brown, dark blue, light blue, dark green and pale green. And in between two colours, there is a colour transition. Therefore, the wrappers should be bright and gorgeous at that time. In a width of $1 \mathrm{~cm}$ there are 20 to 22 silk threads, all Z-twisted. The sutra wrappers are sometimes finished by textiles such as weft-faced compound twill or warp-faced compound twill, which mostly shows floral pattern.

Why paper documents were attached to bamboo sutra wrappers? Except for protection, there should be social reasons. In ancient times, papers and writing brushes are extremely precious. A legend says that when Cang Jie (a legendary person) created Chinese characters, the heaven was moved into grain tears since information can be spread quickly; ghosts were scared into deep night tears since they have nowhere to hide. Therefore, paper was considered as a symbol of wisdom. Another reason is that temples in Dunhuang are usually lack of paper because of desolate location and poor traffic condition, so it is wasteful to throw away paper with writing. The third reason is that although lack of paper, the temple in Dunhuang has a plenty of papers with writing, mostly of which are sutras donated by Buddhist believers. And finally, sutras were frequently used then reference was necessary, so it is reasonable to paste papers with writing to the back of sutra wrappers.

\section{Techniques for Bamboo Sutra Wrappers}

\subsection{Weaving Technique}

The bamboo sutra wrappers are made by the technique of twining with silk threads and bamboo splints. Two sets of silk threads in different colours are required in the twining process, when the silk threads are twined once, the colours are alternately arranged while they are twined twice, the colour is the same. By twining, patterns were formed (see fig4.). After observed the sutra wrapper fragments and the repeat of the patterns, most of which are flowers and geometries, some are Chinese characters (see Figure 5.).
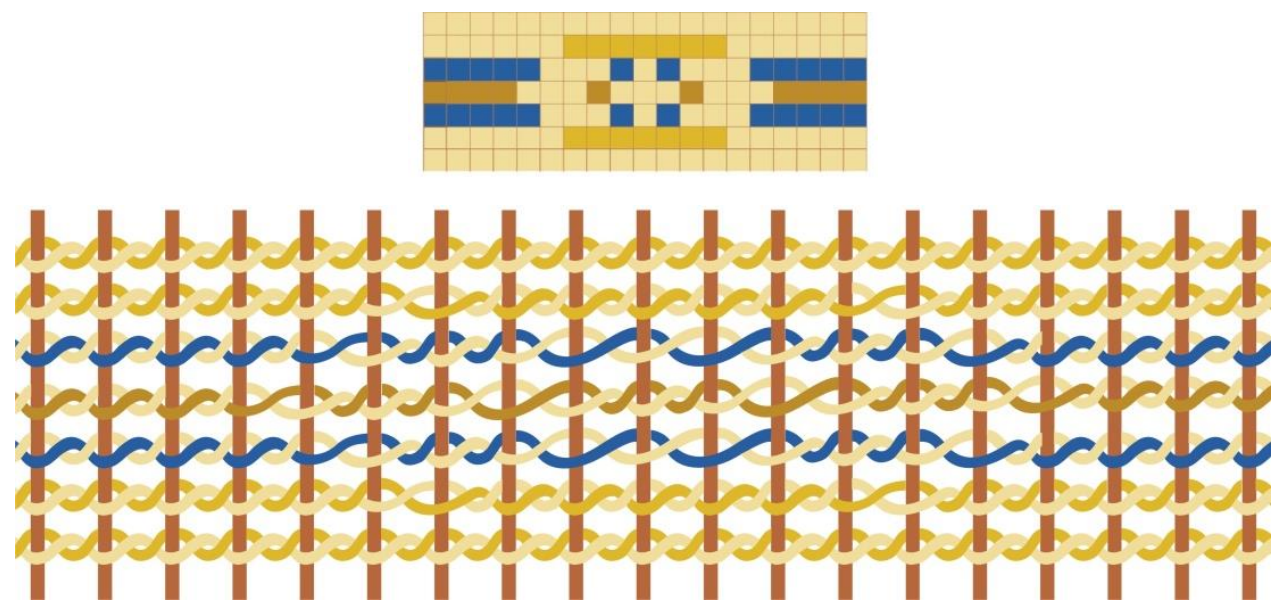

Figure 4. Weaving technique of changing colours

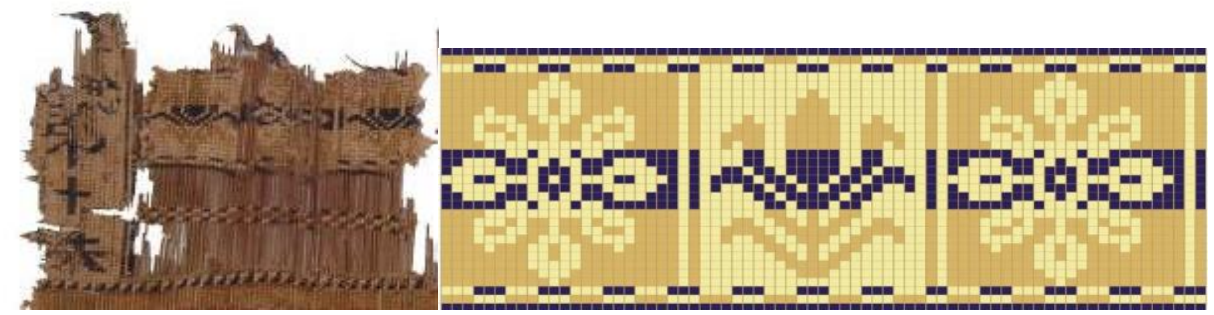

Figure 5. Reconstructed patterns on an sutra wrapper in the collection of Lüshun Museum

\subsubsection{The Start of Twining}

When making Bamboo sutra wrappers, bamboo splints are laid in parallel then silk threads are twined with the help of tools like needles. At the beginning of the wrapper, two threads of different colours are crossed then 
folded in opposite directions to from a loop and the first splint is arranged in the loop. Such a start is the firmest and the back side of the wrapper looks simple. (see Figure 6).

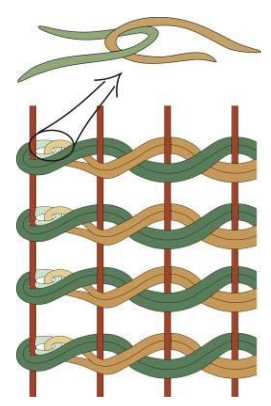

Figure 6. The start of twining

\subsubsection{The Connection of Threads}

Till the end of threads, new threads should be added. The connection of the threads is made in this way: a length of $5-7 \mathrm{~cm}$ from the end of the previous threads overlap a length of $5-7 \mathrm{~cm}$ from the beginning of the newly added threads (generally four threads in total at the meeting point) then continue twining. Such a way of thread connection ensures a secure and firm linkage and a neat view of the back and avoids bulges caused by knots.

\subsubsection{The Finish of Twining}

When silk threads are approaching the final bamboo splint, some finishing work should be done. For some sutra wrappers, threads wound around the final 10-15 bamboo splints at the back side are of deeper colours than those at the rest part, and some sutra wrappers remain fragments of paper attached to the back the finishing area (see Figure 7.). It is concluded that when finishing, silk threads are tied first then for the purpose of stabilization, paper is pasted to the final bamboo splints with glue or other sticky liquid.

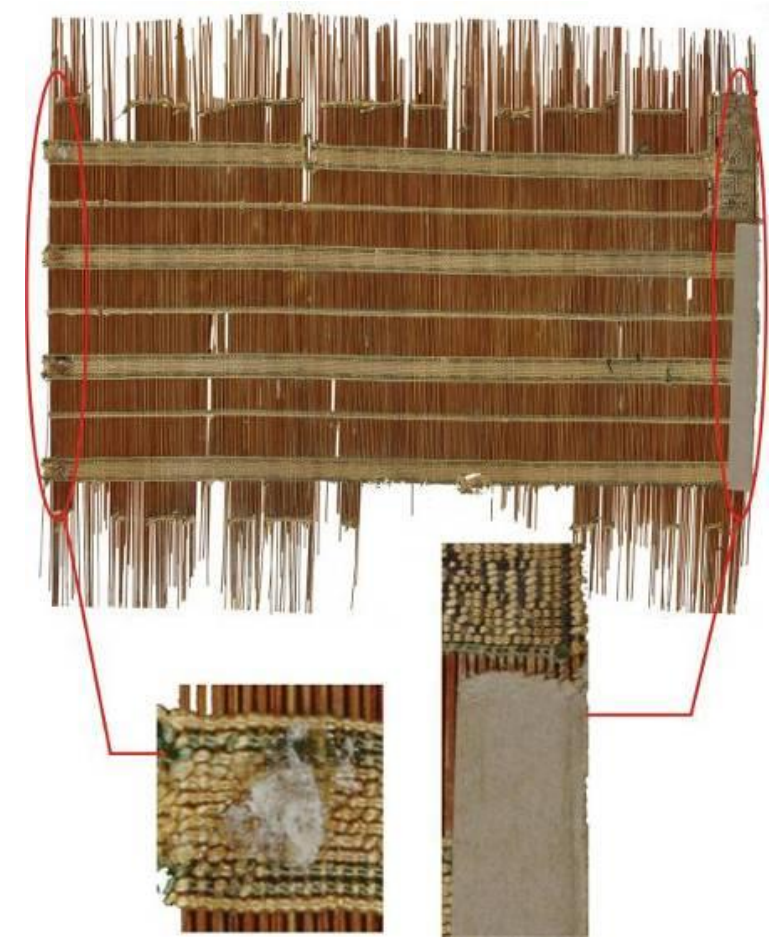

Figure 7. Wrapper for the Prajñāpāramitā Sutra, the back

\subsection{Technique for Creating Chinese Characters}

Sutra wrappers unearthed from Dunhuang are almost produced in the same twining technique but some Chinese characters on those wrappers are created in a slight different way. In order to imitate the brush stroke in Chinese calligraphy, the starting and finishing parts of the characters require a special technique. And those characters are usually arranged in rectangles, therefore, they can't be woven along a direction, namely only from left to right or 
just from right to left.

The brush strokes at the beginning or the end of a character are created by the silk threads remaining in between two bamboo splints instead of tightly completely being wound around the bamboo splints after twining (fig8.). Generally, both the silk threads on the front and reverse should be pulled taut, especially those at the reverse side, but when special effect is required, for example, for the purpose of creating an effect like brush strokes, the threads at the back can be loosened but keep the threads on the front tight. This technique is proven by reconstruction (see Figure 9.).

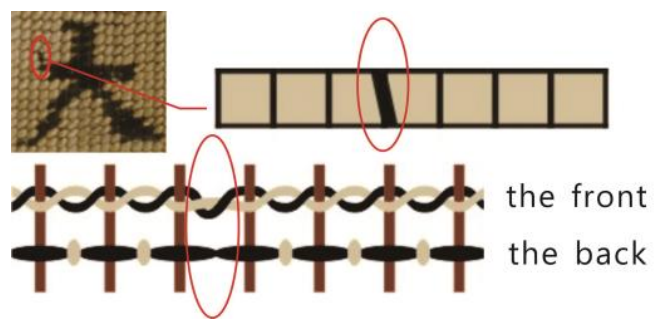

Figure 8. Technique for creating brush stroke
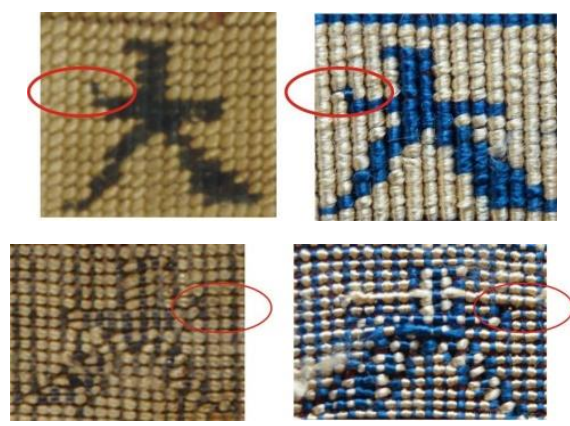

Figure 9. A brush stoke shown by a bamboo sutra wrapper, the front and back (the left two are from the original and the right two are from a replica)

Characters are woven in rectangle frames. Therefore, the threads creating characters are not woven along a direction; instead, after a set of threads reaches the frame, it returns and weaves backwards (see fig 10.). In addition, the threads in the rectangle are thinner than those outside. At the points where the frame and the main panel outside the frame meet, the threads for the main panel joined the threads for the rectangular frame for the sake of firmness.

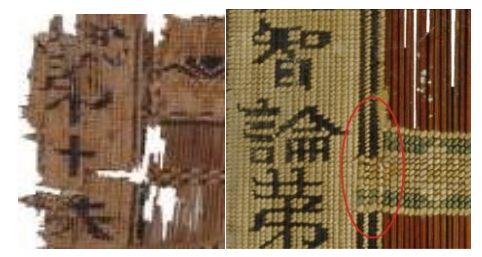

Figure 10. Points where frame and the main panel meet

\section{The Use of Bamboo Sutra Wrapper}

Twined bamboo sutra wrappers are easy to use. Since sutra wrappers are specifically woven for Buddhist documents, therefore they just match the size of documents. To use a wrapper, firstly keep the wrapper upside down then put a Buddhist documents on the wrapper and finally rolls the document with the wrapper from the end to the start (See Figure 11).

The patterns on the wrappers vary from each other. A wrapper may have a title either woven or written on a paper tag then pasted to the wrapper, such as Da zhi lun di yi zhi (indicating this is the first wrapper for the Prajñ āpāramitā Sutra ) or “吅第十帙” $\square \square$ di shi zhi (indicating this is the tenth wrapper for $\square \square$ Sutra). Temple libraries store documents according to their titles so monks can access any one of the documents easily. Such wrappers are beautiful and useful. They can protect the document and make the documents convenient to read. 


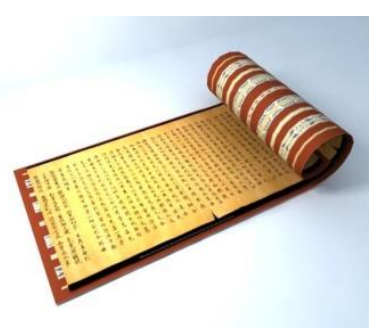

Figure 11. The use of bamboo sutra wrapper

\section{Japanese and Korean Sutra Wrappers of the Same Period}

With the spread of Buddhism, Buddhist sutra wrappers also became popular in Japan and Korea. Their weaving techniques are similar to those in China. According to their pattern, Japanese sutra wrappers fall into two types. One is similar to those found in Dunhuang. They are formed by alternately arranged wide and narrow strips of patterns. The other shows large patterns instead of patterns in strips. The latter is more difficult and takes more time to make but they are very impressive and gracious.There are two big differences in technique between Chinese sutra wrappers and Japanese ones. One is twining direction and the other is whether all bamboo splints are covered or not.

Firstly, on Chinese sutra wrappers both the threads, including threads at the back or in the front, are twined in the same direction, namely from lower left to upper right while on Japanese ones threads are twined from upper left to lower right but the final twine is from lower left to upper right.

Secondly, the bamboo splints on all Chinese sutra wrappers are covered with threads on both sides while Japanese covers have some parts on the front side not covered with threads if the colour of the bamboo splints is the same as that of the threads. The threads are hidden behind the bamboo splints without twining. When many bamboo splints are skipped, the threads are loose and the wrapper is easy to get twisted and distorted. (See Figure 12 and Figure 13).
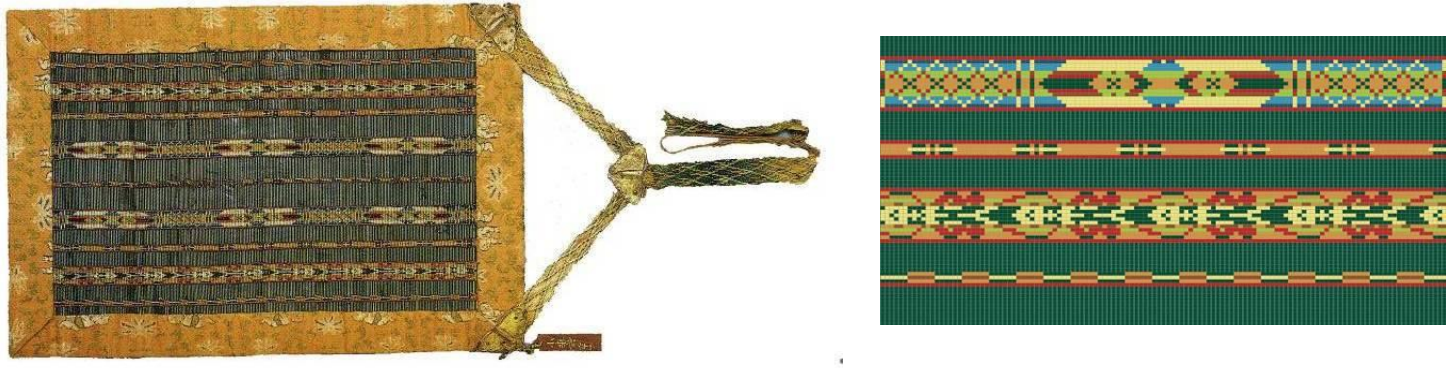

Figure 12. The reconstructed pattern on a bamboo sutra wrapper edged with jin-silk, Tang dynasty style, Japan Heian Period (C.E. 794 -1192)

(The left figure is from Techniques and Beauty of Japanese Dyeing and Weaving in Japanese)
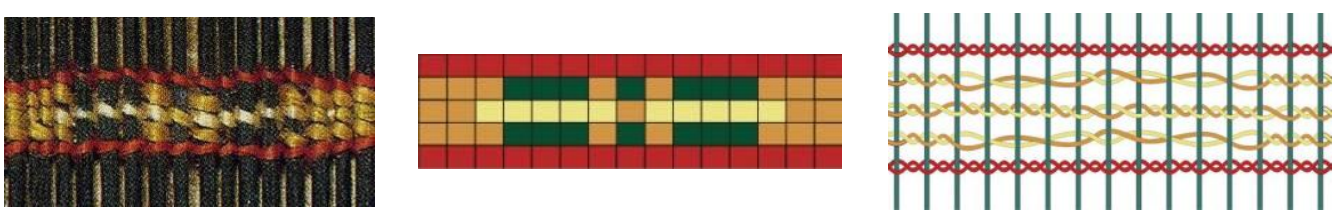

Figure 13. The technique for making Japanese bamboo sutra wrapper

Songgwang-sa temple in Korea also keeps two Buddhist sutra wrappers. They are also in the shape of rectangle and bamboo splints are held together by bands of silk threads with warp twinning method. They are different from Chinese sutra wrappers for the patterns are very big. An independent floral pattern is formed by 60 bamboo splints in the warp direction and about 50 silk threads in the weft direction. (see Figure14). 


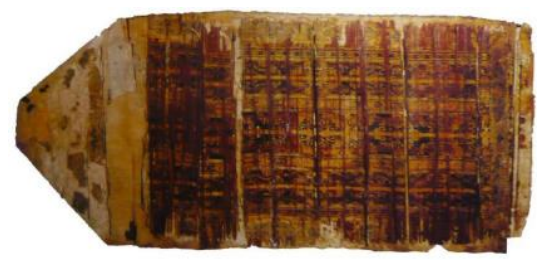

Figure 14. Bamboo sutra wrapper in the collection of Songgwang-sa, Goryeo Dynasty (10th-11thC) (the figure is from Buddhist Sutra Wrapper from Songgwang-sa)

\section{Conclusion}

Bamboo sutra wrappers of the Tang and Song dynasties (CE 618-1279) are representatives of twined works. They are rectangular in shape and their sizes are determined by the Buddhist documents. The motifs on wrappers are popular in the Tang dynasty such as flowers, scrolled grasses and geometrical patterns. The colours are plentiful and in between two colours there is a colour transition, thus the patterns are very natural. Reddish brown bamboo splints are used as wefts and silk threads of different colours are used as warps and the wrappers are created by warp twinning method. Some wrappers are edged with textile or pasted with paper. Because the wrappers are different in colour, pattern and with different characters or numbers, it is easy for monks to find the Buddhist documents.

\section{References}

Fang, G. C., \& Xu, P. L. (1995). Dunhuang Jingzhi, Dunhuangxue jikan, (1), 1-8.

Gu Ye Wang. (Southern Dynasties Liang (CE 502 - 557)), Yu Pian. Beijing: Zhonghua Book Company.

Kyoto National Museum. (1987). The beauty of Japanese dyeing and weaving. Photo Joint-stock Company.

Liu An. (Western Han). Huainanzi ·benjingxun. Beijing: Zhonghua Book Company.

Lu You. (Southern Song). Wei nan wen ji .Hangzhou: Zhejiang Ancient Books Publishing House.

Shen, L. Y. (2003). The sutra wrappers from Songguang Temple. Museum of Songguang Temple and Korea Foundation.

Xiao Tong. (Southern Dynasties). XianQin Han WeiJin Nanbeichao shi.Liang shi. Beijing: Zhonghua Book Company.

Xu Shen. (Eastern Han Dynasty). Shuowen jiezi. Beijing: Zhonghua Book Company.

\section{Copyrights}

Copyright for this article is retained by the author(s), with first publication rights granted to the journal.

This is an open-access article distributed under the terms and conditions of the Creative Commons Attribution license (http://creativecommons.org/licenses/by/4.0/). 